\title{
COMPUTER SIMULATION OF DEFORMATION AND FRACTURE CONDITIONS DURING THE DETAIL ROLLING WITH A FLANGE WITH INCLINED ROLLS
}

\author{
Sergey A. Ignatiev - Pavel V. Kononov* - Dmitry S. Levashov - Eduard Kh. Muratbakeev - \\ Konstantin O. Glazunov
}

${ }^{1}$ Department of Descriptive Geometry and Graphics, Faculty of Basic and Human Sciences, Saint-Petersburg Mining University, 2, 21 st Line, St Petersburg 199106, Russia

\begin{tabular}{|c|c|}
\hline ARTICLE INFO & Abstract: \\
\hline $\begin{array}{l}\text { Article history: } \\
\text { Received: } 28.6 .2019 . \\
\text { Received in revised form: } 26.7 .2019 . \\
\text { Accepted: } 26.7 .2019 .\end{array}$ & $\begin{array}{l}\text { An adequate computer model of the process of rolling flange } \\
\text { details with inclined rolls has been built in the software package } \\
\text { DEFORM-3D. The analysis of the stress-strain state of a detail } \\
\text { with a flange was performed. The rheological properties of the }\end{array}$ \\
\hline $\begin{array}{l}\text { Keywords: } \\
\text { Rotary forging } \\
\text { Details with flanges } \\
\text { Cockcroft-Latham } \\
\text { Forming of metal } \\
\text { DEFORM-3D } \\
\text { Computer simulation }\end{array}$ & $\begin{array}{l}\text { alloy L63 }(62-65 \% \mathrm{Cu}, 34.5-38 \% \mathrm{Zn}) \text { were experimentally } \\
\text { studied. Value limits of the Cockcroft-Latham fracture criterion } \\
\text { for the alloy L63 are determined. }\end{array}$ \\
\hline DOI: https://doi.org/10.30765/er.1483 & \\
\hline
\end{tabular}

\section{Introduction}

Currently, with the widespread use of computer modeling and the development of various finite element (FE) software systems, studies of rotational technological processes of pressure treatment of materials are being actively conducted [1-4].

The peculiarity of flanging processes on cylindrical workpieces is the presence of a local deformation zone with a complex stress-strain state (SSS). At certain stages of rolling, the workpiece may be destroyed, which depends on the rheological properties of the workpiece material, the SSS scheme, loading conditions and tooling geometry.

There are computer models of rolling cylindrical blanks, which consider the complex of physical and mechanical process features under study and allow you to calculate the parameters of the deformed state at each point of the workpiece to predict the likelihood of cracking, folding and loss of the workpiece stability. However, in the libraries of fracture criteria describing the destruction of metals during plastic deformation, due to the great diversity and peculiarities of technological processes of metal forming, there is no uniform method for determining the limiting values of SSS in the deformation zone [5-12]. In work [13] the estimation methods of critical damage value criterion of destruction by means of physical modelling of deformation process on a complex Gleeble-3800 are considered.

The purpose of this work was to develop non-destructive modes of rolling out details with flanges by inclined rolls using mathematical and physical modeling methods.

\section{Experimental investigation}

\subsection{Experimental-calculation estimation of the Cockcroft-Latham fracture criterion critical damage value}

Normalized Cockcroft-Latham criterion of destruction is based on the analysis of the total work of strain per unit volume at the destruction point [14-16]:

\footnotetext{
* Corresponding author.

E-mail address: kononov_pv@pers.spmi.ru.
} 


$$
C_{\mathrm{C}-\mathrm{L}}=\int_{0}^{\varepsilon_{i}} \frac{\sigma_{1}}{\sigma_{i}} d \varepsilon_{i}
$$

where $\mathcal{E}_{i}$-accumulated strain; $\sigma_{1}-$ max principal stress; $\sigma_{i}-$ effective stress (von Mises stress). Metal destruction condition:

$$
\int_{0}^{\varepsilon_{i}} \frac{\sigma_{1}}{\sigma_{i}} d \varepsilon_{i} \geq C_{\mathrm{C}-\mathrm{L}}^{\mathrm{CR}}
$$

where $C_{\mathrm{C}-\mathrm{L}}^{\mathrm{CR}}$ - critical damage value of the Cockcroft -Latham criterion, corresponds to the destruction point. It should be noted that $C_{\mathrm{C}-\mathrm{L}}^{\mathrm{CR}}$ is a structure sensitive quantity and depends on temperature and deformation rate. For the determination of $C_{\mathrm{C}-\mathrm{L}}^{\mathrm{CR}}$ in this work, an experimental calculation technique was used [17, 18], that includes stretching the pieces before destruction at the Gleeble-3800 complex and finite-element modelling of the piece stretching before the process of destruction. While modeling the conditions of the sample stretching, a rigid-plastic medium with hardening was adopted as a model of the process material. Its behavior at given temperatures and strain rates is described by the dependences of the true stresses from the true strains.

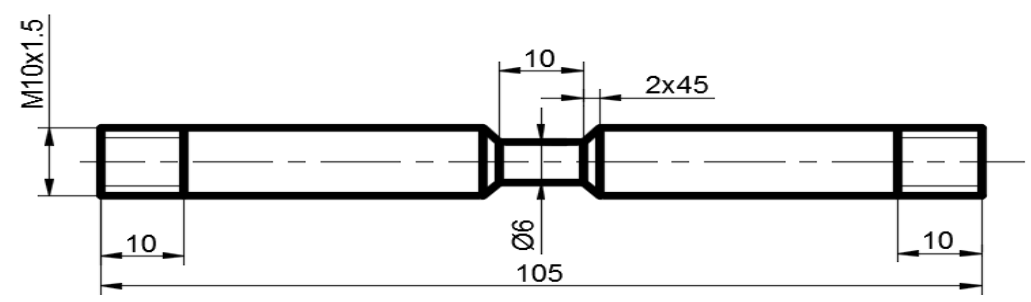

(a)

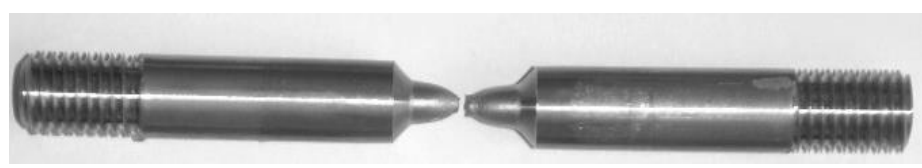

(b)

Figure 1. The geometric dimensions of the test workpiece and it's appearance after destruction.

Pieces of special geometry from L63 brass, a copper-zinc alloy, processed by the method of melting, the chemical composition of which is given in Table 1, were tested for tensile strength before destruction in Figure 1 . The tests were carried out at room temperature in the strain rate range from $0.1-20 \mathrm{~s}^{-1}$. According to the obtained data, the strain rate has almost no effect on the course of the experimental curves in Figure 2. In all tested pieces, the diameter at the point of destruction was $2.8-2.85 \mathrm{~mm}$. Taking it into consideration, we found out the true strain at which the pieces were destroyed [19-20]:

$$
\varepsilon_{1}=-\ln (1-\psi)=\ln \left(\frac{1}{1-\psi}\right)=\ln \left(\frac{1}{1-0.78}\right)=\ln (4.55)=1.51
$$

where $\psi=\left(F_{0}-F_{\mathrm{k}}\right) / F_{0}=0.78$ is the relative narrowing in the neck, where $F_{0}=\pi D_{0}^{2} / 4$ is the cross-sectional area of a piece before stretching; is the area of the neck of the specimen in the final stage of destruction; $D_{0}=$ $6 \mathrm{~mm}$ is the diameter of the working part of a piece before stretching. $D_{\mathrm{K}}=2.8 \mathrm{~mm}$ is the diameter of the neck piece in the final stage of destruction. 


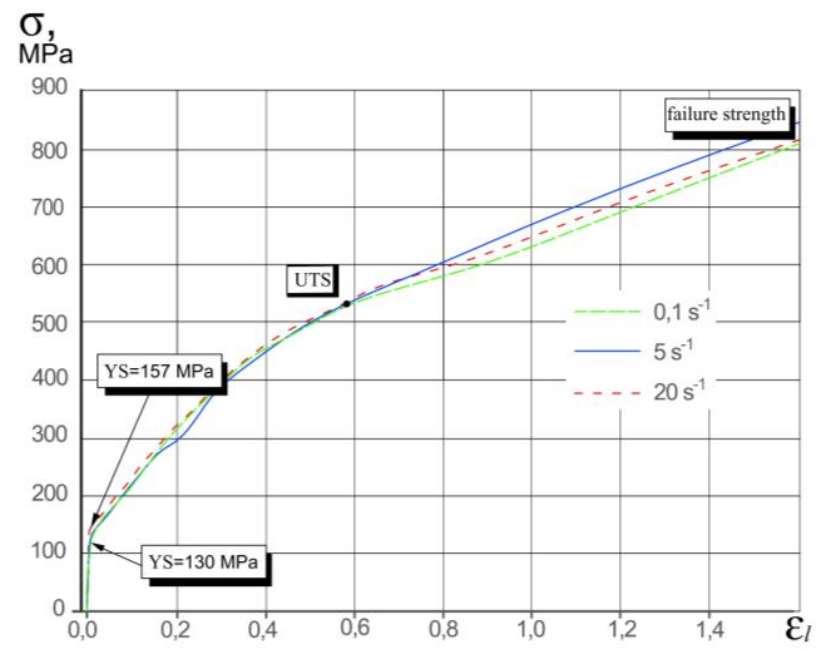

Figure 2. True stress-strain curves for the L63 alloy, obtained at different strain rates by tensile tests at temperature $20^{\circ} \mathrm{C}$.

Table 1. The chemical composition of brass in \% (according to GOST 15527-2004), analogue American C27400, German CuZn37.

\begin{tabular}{|c|c|c|c|c|c|c|c|c|}
\hline Alloy & $\mathrm{Cu}$ & $\mathrm{Fe}$ & $\mathrm{P}$ & $\mathrm{Pb}$ & $\mathrm{Sb}$ & $\mathrm{Bi}$ & $\mathrm{Zn}$ & Impurities \\
\hline $\mathrm{L} 63$ & $62 \ldots 65$ & 0,2 & 0,001 & 0,07 & 0,005 & 0,002 & rest & 0,5 \\
\hline
\end{tabular}

The critical damage value of $C_{\mathrm{C}-\mathrm{L}}^{\mathrm{CR}}$ are estimated by the method of successive selection of finite diameters in the place of destruction virtual pieces during modeling in the DEFORM-2D package. Parameters were put into the model: the rheological properties of the workpiece (Figure 2), the temperature of the tool and the workpiece $-20^{\circ} \mathrm{C}$, the contact of the workpiece with the upper and lower tool stick in condition.

The mathematical model of the workpiece environment is a rigid-plastic medium with hardening, the finite element mesh contains more than 10,000 elements. The upper and lower instrument is specified in the form of an absolutely solid body. The lower tool remained stationary. Constant value speed of the upper tool $15 \mathrm{~mm} / \mathrm{sec}$. As a result, the critical damage value of the destruction criterion for the selected range of strain rate was estimated by the method of selecting the final diameter of the virtual piece at the destruction site $C_{\mathrm{C}-\mathrm{L}}^{\mathrm{CR}}=1.75$ in Figure 3 a. The calculations showed that the average value of the effective strain at the destruction point in Figure $3 \mathrm{~b}$ is equal to the true strain calculated by formula (3).

(a)

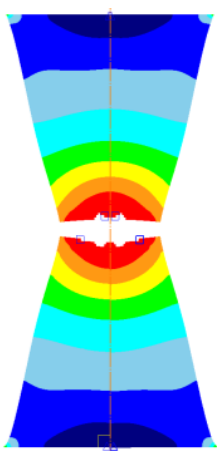

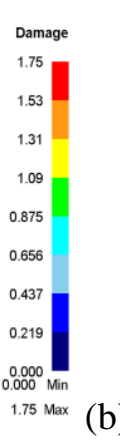

(b)

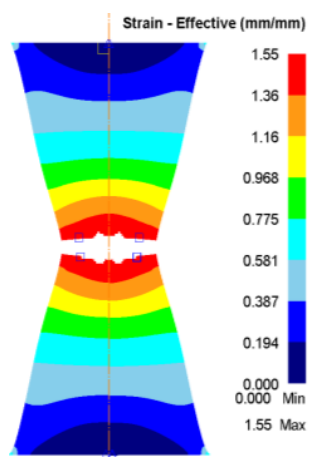

Figure 3. The values of the criterion of destruction (a) and the of effective strain ( $b$ ) on the stage of final destruction $C_{\mathrm{C}-\mathrm{L}}^{\mathrm{CR}}=1.75$.

\subsection{Statement of the task of computer simulation of the process of rolling a part with a flange}

The process of forming a detail with a flange consists of three stages in Figure 4 [21, 22]. The workpiece 3 is mounted on the ejector 4 and placed in the matrix 2 . To increase rigidity, the ejector 4 is supported by a 
sleeve 5 fixed by the back stop of the machine. In a first step, the matrix 2 is rotated with the workpiece 3 . Further, the deforming roll 1 is lead to the workpiece at an angle of $\beta_{1}$, is rotated out and is formed into a truncated cone. In the second step, a preliminary flange is formed: the deforming roller 1 is positioned at an angle $\beta_{2}$ to the matrix axis. At the final, third, stage, pre-flange is rolled out by the second roll 6 , placed at an angle $\alpha$ to the matrix axis 2 , and then the workpiece acquires the required shape.

Details with the flange were obtained at different angles of inclination of the rolling rolls. In some cases after the first stage of rolling out the workpiece could already appear in the cone base area in Figure 5, a and further rolling out of the workpiece was impossible. Cracking indicates an active metal flow in the radial direction by reaching the ultimate plasticity values of the material. At some angles of inclination after the third stage of rolling, the diameter of the resulting flange of the workpiece did not exceed the initial diameter of the workpiece in Figure 5, b. In this case, the formation of the flange happens due to the metal flow in the sleeve portion of the workpiece, which does not contribute to the flange formation of the maximum possible dimensions with the ratio $D_{\mathrm{F}} / D_{\mathrm{S}}=2.0\left(\mathrm{D}_{\mathrm{F}}, \mathrm{D}_{\mathrm{S}}\right.$ - diameters of the flange and sleeve portion) and causes the metal destruction.

Thus, the influence of the angle of inclination of the rolling rolls on the metal flow in the radial and axial direction has been established experimentally. To develop non-destructive modes of rolling out of the required flange, it is necessary to establish a range of inclination angles of the rolling roll to the axis of the workpiece at each stage of formation. To select optimal modes of non-destructive rolling and to reduce the volume of experimental research, an approach based on computer and physical modelling of the flanging process is proposed.

To simulate the assembly of a rolling unit, used the SolidWorks software. The assembly modeled in it was saved in the. stl format and loaded into the DEFORM. A cylindrical workpiece with a stepped outer surface with diameters of $\varnothing=45 \mathrm{~mm}$ and $\varnothing=35 \mathrm{~mm}$ and an internal hole of $\varnothing=25 \mathrm{~mm}$, with a height of 45 $\mathrm{mm}$ was deformed according to the scheme of angular rolling with a roll with a diameter of $\varnothing=150 \mathrm{~mm}$. The ejector in the form of a rod has a diameter of $\varnothing=25 \mathrm{~mm}$, a cylindrical matrix with outer diameter $\varnothing=$ $80 \mathrm{~mm}$, inner diameter $\varnothing=35 \mathrm{~mm}$.

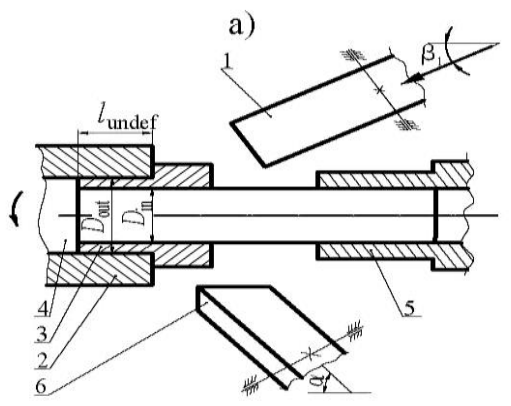

c)

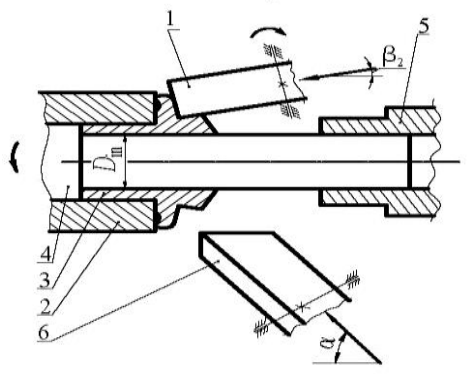

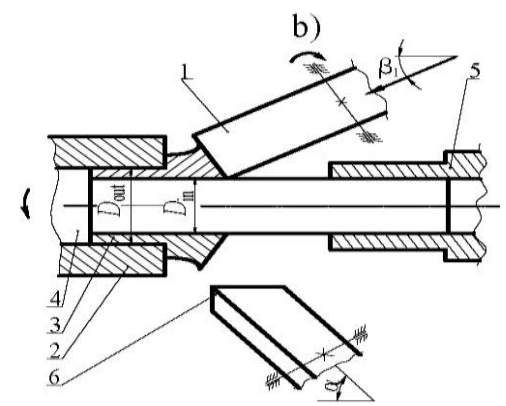

d)

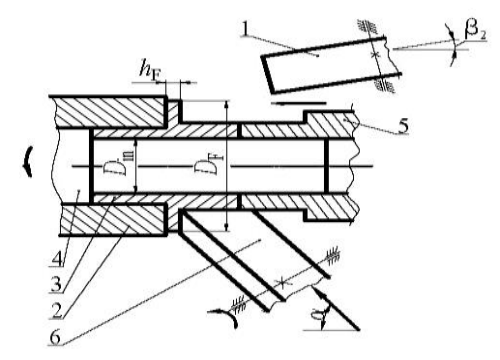

Figure 4. Sequence of formation of a detail with a flange by rolling out: $a$-starting position of the rolls; $b$, $c, d$-first, second and third stages of formation; 1 -deforming roll; 2 - matrix; 3 -workpiece; 4 ejector; 5 -sleeve; $h_{F}$-flange height; $l_{u}$-length of rolled and unrolled sleeves; $D_{S}, D_{F}$ - external diameters of sleeve parts and flange; $D_{\text {OUT }}$ - external diameter unrolled rolls; $D_{I N}$ - inner diameter of initial workpiece; $\beta_{1}$ and $\beta_{2}$-inclination angles of the first deforming roll in the first and second stages of rolling out; $\alpha$-inclination angle of the second deforming roll in the third stage of rolling 


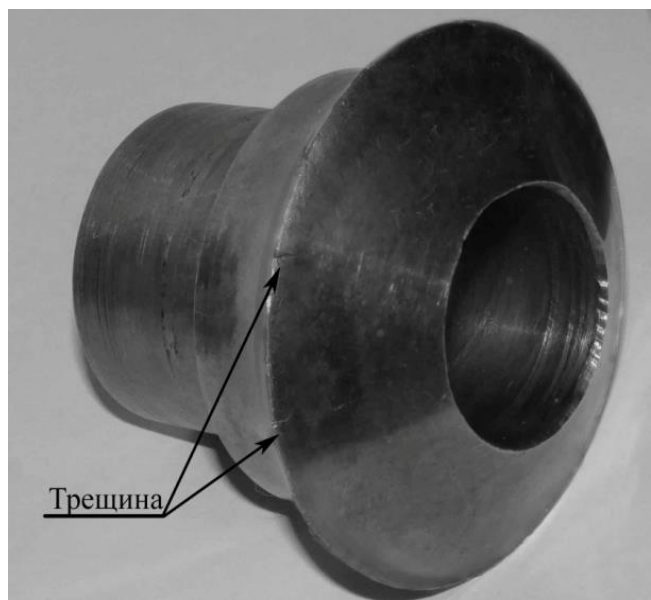

(a)

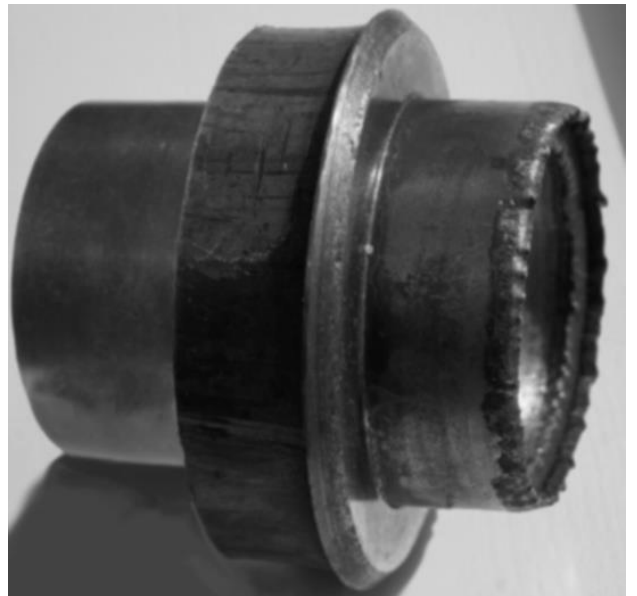

(b)

Figure 5. The results of incorrect installation of the angles of the rolling rolls: a-fractures in the workpiece after the first stage of formation the flange; $b$-diameter of the flange does not exceed the initial diameter of the workpiece (third stage of formation).

To simulate the rolling unit assembly, used the SolidWorks software. The assembly modeled in it was saved in the. stl format and loaded into the DEFORM. A cylindrical workpiece with a stepped outer surface with diameters of $\varnothing=45 \mathrm{~mm}$ and $\varnothing=35 \mathrm{~mm}$ and an internal hole of $\varnothing=25 \mathrm{~mm}$, with a height of $45 \mathrm{~mm}$ was deformed according to the scheme of angular rolling with a roll with a diameter of $\varnothing=150 \mathrm{~mm}$. The ejector in the form of a rod has a diameter of $\varnothing=25 \mathrm{~mm}$, a cylindrical matrix with outer diameter $\varnothing=$ $80 \mathrm{~mm}$, inner diameter $=35 \mathrm{~mm}$. Since the rolling process is accompanied by large plastic deformations, the Siebel friction law was specified on the contact surface (in the Deform package, the Siebel friction law corresponds to the Shear model).

The friction index was taken to be 0.15 , the temperature of the workpiece and the tool was $20^{\circ} \mathrm{C}$. The model of the workpiece environment is defined as rigid plastic with hardening, the rheological properties of the copper alloy L63 were set in the form of a strain hardening curve at various strain rates, obtained experimentally on the Gleeble-3800 complex (Figure 2), the number of finite elements of the workpiece is more than 60,000, and in the volume of the deformable part of the workpiece a special area was created with a denser mesh, the tool environment model is rigid. The deforming roll feed $0.5 \mathrm{~mm} / \mathrm{s}$, the rotation of the roll was due to friction on the contact with the workpiece, in the Rotation section, the torque parameter was chosen and the value was set to $0.01 \mathrm{Nm}$. The rotation (angular) velocities values of the matrix, ejector and the inner surface of the workpiece were $7 \mathrm{rad} / \mathrm{sec}$. An example of defining boundary conditions in displacements is shown in Figure 6.

\section{Results and discussion}

Based on the results of computer simulation, non-destructive modes were established with a range of variation in the inclination angle of the rolling roll in the first stage $\beta_{1}=25-35^{\circ}$ in Figure 7 . When $\beta_{1}<25^{\circ}$, cracks can form in cone base, which indicates the active flow of metal in the radial direction and the depletion of the workpiece material plasticity resource, and subsequent rolling out of such a workpiece is impossible. In the case of $\beta_{1}>35^{\circ}$, the metal flow is directed mainly to the sleeve portion part of the workpiece. As a result, in the third rolling stage, a part with a flange is formed that does not exceed the diameter of the rolled out portion of the initial workpiece.

The values of the angles of inclination of the rolling roll $\beta_{2}$ in the second rolling step should be chosen from the interval of $10-20^{\circ}$. At $\beta_{2}<10^{\circ}$ and $\beta_{2}>20^{\circ}$, due to the features of the metal flow, the workpiece does not acquire the shape, that is necessary for rolling out the part with the flange in the third stage with the required dimensions $\left(D_{\mathrm{f}} / D_{\mathrm{s}}=2.0\right)$. The final formation of the flange and sleeve portion is carried out in the 
third stage of rolling out. The rational values of the angle of inclination of the rolling roll to the axis of the workpiece are in the interval $\alpha=45-75^{\circ}$.

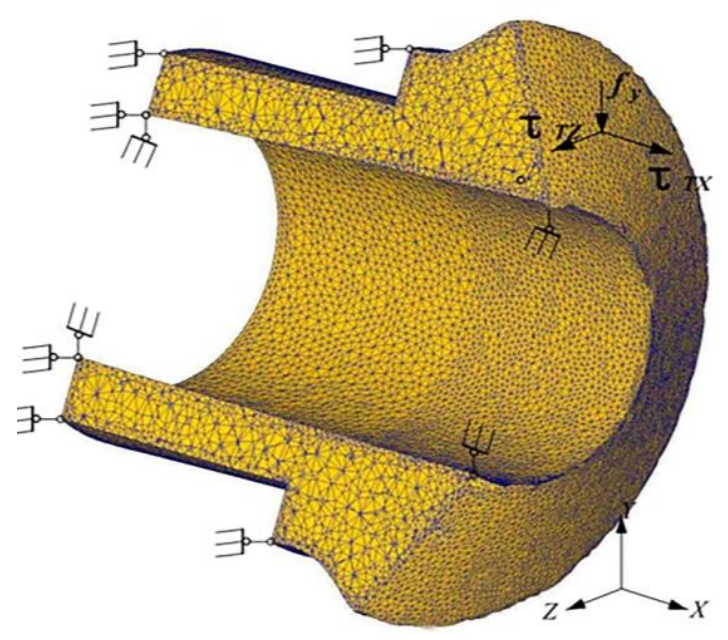

Figure 6. Boundary angle setting scheme.

For $\alpha<45^{\circ}$, the length of the rolled out sleeve part $l_{\mathrm{s}}$ of the workpiece is limited to the value of the ratio $l_{\mathrm{s}} / D_{\mathrm{f}} \leq 0.2-0.22$. In the case $\alpha>75^{\circ}$, it makes it difficult for the metal to flow in the radial direction and limits the dimensions of the flanges formed by the quantity $l_{\mathrm{s}} / D_{\mathrm{s}}=1.2-1.4$. According to the results of computer modeling in the DEFORM-3D software package, tensile stresses act at all stages of rolling out the part with a flange outside the deformation center (DC) (see Figure 7). Analysis of the fields of distribution of accumulated of effective strain showed that the maximum of effective strain is concentrated in the contact layers in Figure 8. In the places of action of the main tensile stresses and maximum values of effective strains, the maximum values of the criterion for destruction of Cockcroft-Latham are observed (Figure 9). The calculated values of the criterion for the study areas of the workpiece are given in the table. It should be noted that these values do not exceed of the threshold limit ones, established experimentally: $C_{\mathrm{C}-\mathrm{L}}^{\mathrm{CR}}=1.75$.

Experiments carried out under laboratory conditions using the proposed rolling out modes showed no destruction in the detail with a flange of the L63 alloy (Figure 10).

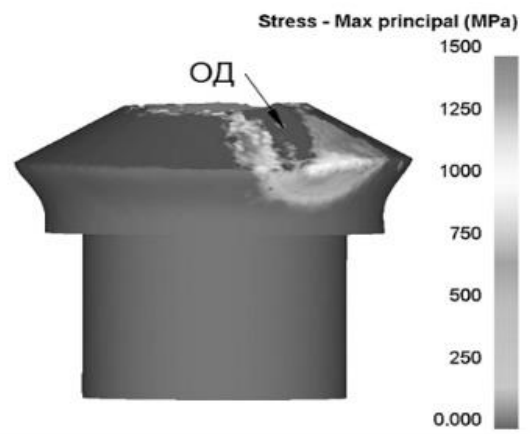

(a)

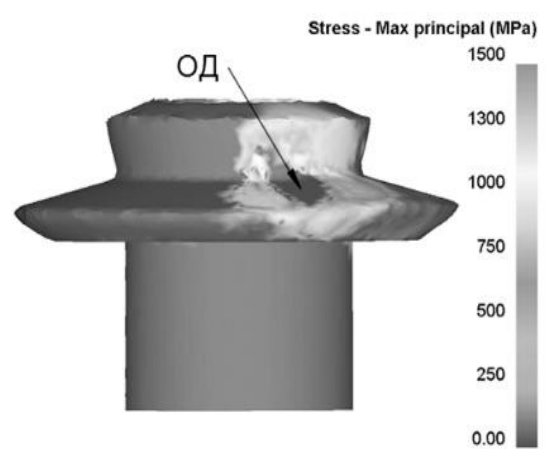

(b)

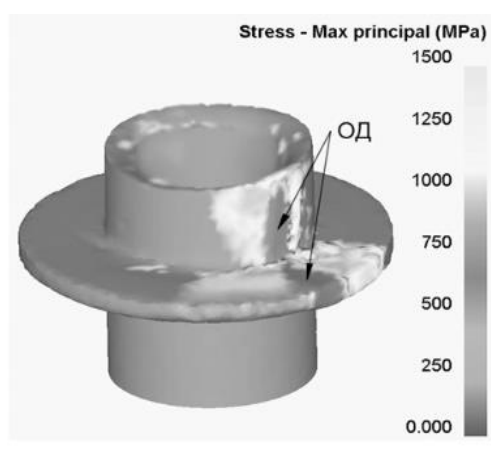

c)

Figure 7. Distribution field of principal stresses: a - first stage of rolling out, angle of rolls $\beta 1=30^{\circ} ; b-$ second stage, $\beta_{2}=15^{\circ} ; c-$ third stage, $\beta_{2}=45^{\circ}$. 


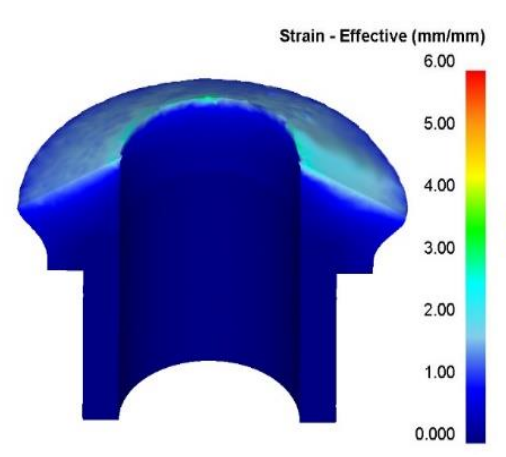

(a)

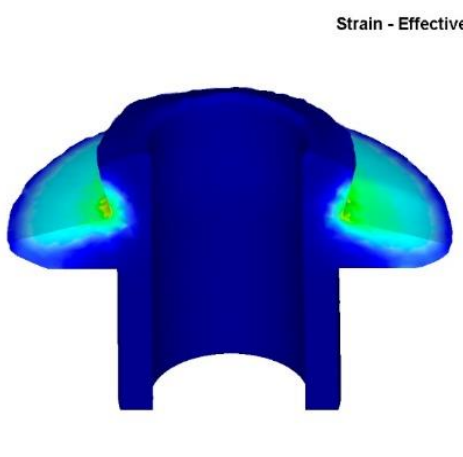

(b)
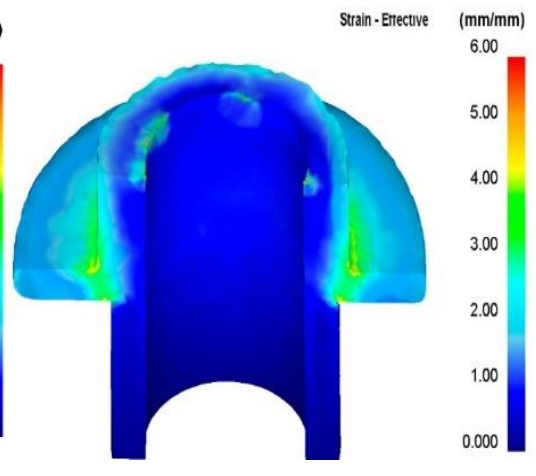

(c)

Figure 8. Distribution field of effective strain values: $a$ - first stage of rolling out, angle of rolls $\beta_{1}=30^{\circ}$; $b-$ second stage, $\beta_{2}=15^{\circ} ; c-$ third stage, $\beta_{2}=45^{\circ}$.

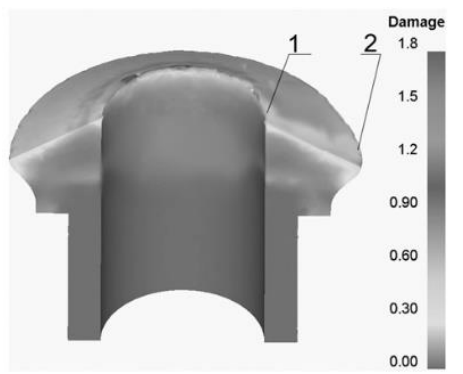

(a)

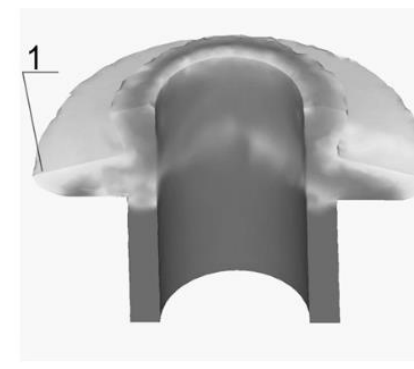

(b)

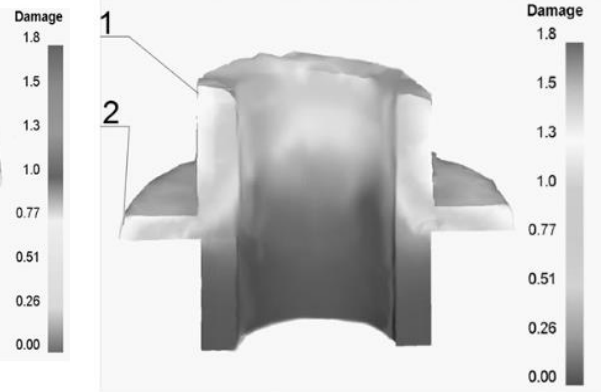

(c)

Figure 9. Distribution field of Cockcroft-Latham (see Table 2) criterion for the first (a), second (b) and third (c) stages of rolling out detail with flange: 1,2 - concentration areas of the maximum calculated values of the criterion.

Table 2. The values of the Cockcroft-Latham criterion for the investigated workpiece areas (see Figure 9).

\begin{tabular}{ccc}
\hline Stage rolling & $\mathbf{1}$ & Study areas \\
& $\mathbf{1}$ & $\mathbf{2}$ \\
2 & 0.42 & 0.33 \\
3 & 0.71 & - \\
\hline
\end{tabular}

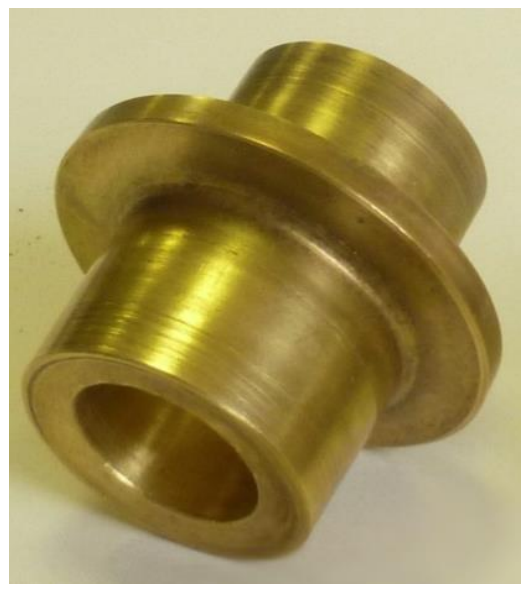

Figure 10. Finished part. 


\section{Conclusion}

1. With the help of computer simulation of the rolling-out process in the DEFORM-3D software complex, patterns of shape formation are established and a numerical study of the evolution of effective strain fields of parts with flanges is performed.

2. A dimensionless Cockcroft-Latham criterion was used to predict damage. Its critical damage value, determined from the true failure stress at the center of the neck during the tensile test for alloy L63, was $C_{\mathrm{C}-\mathrm{L}}^{\mathrm{ex}}=1.75$. The effective strain field in the neck is calculated in the DEFORM-2D software package. The forecast is confirmed by the absence of cracks during rolling out.

3. Using the dimensionless Cockcroft-Latham criterion, an analysis of the possible destruction of the workpiece material at all stages of deformation is done. The modes of rolling out parts with flanges, ensuring their quality, meeting the technical requirements are established.

\section{References}

[1] Aksenov, L.B., Kunkin, S.N.: Development of rotary forging machines: from idea to additive technologies, Sciences of Europe (Praha, Czech Republic), 2 (2016), 7, 4-11.

[2] Bartincki, J.: The theoretical and experimental research of rolling-extrusion process, Lublin Univer. Tech., Lublin, 2009.

[3] Vostrov, V.N., Kononov, P.V.: Finite-element simulation of flanging in the deform $3 d$ software package, Russian Metallurgy (Metally), 5 (2016), 461-466.

[4] Maksarov, V.V., Olt, J.: Dynamic stabilization of machining process based on local metastability in controlled robotic systems of CNC machines, Journal of mining institute, 226 (2017), 446-451.

[5] Kolmogorov, V.L.: Numerical modelling of large plastic deformations and fractures of metals, (2003), 2, 4-16.

[6] Kolmogorov, V.L.: Mechanics of metal processing by pressure, Ural STU, Ekaterinburg, 2001.

[7] Ogorodnikov, V.A. Resource of plasticity in pressure processing, Higher School, Kiev, 1983.

[8] Gubkin, S.I.: Plasticity deformation of metals, Metallurgy, M., 1961.

[9] Dzugutov, M.I.: Plasticity, its prediction and use in the processing of metals by pressure, Metallurgy, M., 1984.

[10] Oyane, M.: Criteria of ductile fracture strain, J. Soc. Mech. Eng., 11 (1972), 1507-1513.

[11] Liu, A.F. Mechanics and mechanism of fracture: An introduction, ASM Int., USA, 2005.

[12] Zhao, D., Bandstra. J.P., Kuhn, H.A.: A new criterion for fracture prediction in metalworking processes, Concurrent Engineerng Approach to Materials Processng: Proc. Int. Symp., Chicago, 1992, 8, 107-119.

[13] Matveev, M.A.: Physicomechanical analysis of the reasons of formation of edging cracks' in hot rolled sheets of tubular steels, PhD thesis, Tech. Scien. Spb., SPBGPU, 2014.

[14] Cockroft, M.G., Latham, D.J.: Ductility and workability of metals, J. Int. Met, 96 (1968), 33-39.

[15] Botkin, A.V., Valiev R.Z., Stepin P.S., Baimukhametov A.H.: Evaluation of metal damage during cold plastic deformation using the Cockcroft-Latam destruction model, Deformation and destruction of materials, (2011), 7, 17-22.

[16] Skripalenko, M. M., Romantsev, B. A., Galkin, S. P., Skripalenko, M. N., Kaputkina, L. M, Huy, T. B. Prediction of the Fracture of Metal in the Process of Screw Rolling in a Two-Roll Mill, Metallurgist, 61 (2018), 11-12, 925-933.

[17] Mishin, V.V., Shishov, I.A.: Investigation of deformation and fracture for thin beryllium foils under static loading by external pressure, Materials Physics and Mechanics, 36 (2018), 1, 100-113.

[18] Kolbasnikov, N.G., Mishin, V.V., Shishov, I.A., Matveev, M.A., Korchagin, A.M.: Surface-crack formation in the manufacture of microalloyed steel pipe, Steel in Translation, 46 (2016), 9, 665-670.

[19] Bernstein, M.L., Zaimovskii, M.A.: Mechanical properties of metals, Metallurgy, M., 1979.

[21] Vostrov, V.N., Kononov, P.V.: Method of rolling flanges on tubular workpicies, Pat 2499648 RUS., 25.06.2012.

[22] Kononov, P.V. Simulation of the process of angular rolling of the cone at the end of the tubular workpiece, Scientific and technical statements SPBSGPU, 195, 2014, 2, 117-120. 